Sādhanā Vol. 38, Part 5, October 2013, pp. 795-815. (C) Indian Academy of Sciences

\title{
Indian fast reactor technology: Current status and future programme
}

\author{
S C CHETAL and P CHELLAPANDI*
}

Reactor Design Group, Indira Gandhi Centre for Atomic Research, Kalpakkam 603 102, India

e-mail: pcp@igcar.gov.in

\begin{abstract}
The paper brings out the advantages of fast breeder reactor and importance of developing closed nuclear fuel cycle for the large scale energy production, which is followed by its salient safety features. Further, the current status and future strategy of the fast reactor programme since the inception through $40 \mathrm{MWt} / 13 \mathrm{MWe}$ Fast Breeder Test Reactor (FBTR), is highlighted. The challenges and achievements in science and technology of FBRs focusing on safety are described with the particular reference to 500 MWe capacity Prototype Fast Breeder Reactor (PFBR), being commissioned at Kalpakkam. Roadmap with comprehensive R\&D for the large scale deployment of Sodium Cooled Fast Reactor (SFRs) and timely introduction of metallic fuel reactors with emphasis on breeding gain and enhanced safety are being brought out in this paper.
\end{abstract}

Keywords. FBR; SFR; closed fuel cycle; breeding; design and technological challenges; safety features.

\section{Introduction}

The current population of India in the year 2012 is about 1.16 billions, which would stabilize at the level of 1.5 billions by the year 2050, constituting one-sixth of the global population. Per capita electricity in India is low (about $700 \mathrm{kWh} / \mathrm{a}$ ), much less than the world average $(\sim 2400 \mathrm{kWh} / \mathrm{a})$. Hence, the demand for a rapid rise in the electricity generation capacity in the coming decades is beyond a matter of debate, for India to realize its dreams of a sustained growth in economy backed by strong industrial development. Realising its requirements and potential, India is aiming to reach at least a per capita energy consumption of about $2400 \mathrm{kWh} / \mathrm{a}$ with $8 \%$ growth rate by $2031-32$. This means the electricity generation capacity of about $778 \mathrm{GWe}$ by 2031-32 with the projected population of about 1.47 billion by that time. Several scenarios have been examined along with policy initiatives, launching of energy projects aimed at improving energy availability, giving due considerations to the environmental implications of various resources. Comprehensive assessment has established that clean coal, renewable (particularly solar and wind) and nuclear energy are the scalable and suitable options for the country.

*For correspondence 


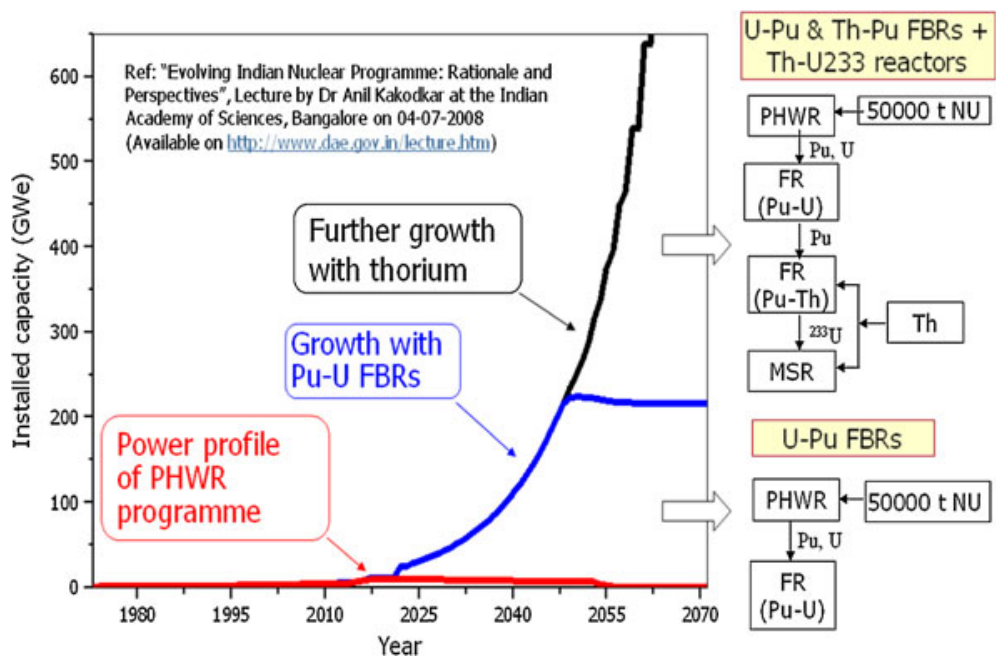

Figure 1. Indian nuclear power growth scenario.

As far as nuclear option is concerned, 'Three Stage Nuclear Power Programme', formulated by Dr. Homi Bhabha still holds good today. This programme involves water reactors, mainly from Pressurised Heavy Water Reactors (PHWRs), in the first stage; Fast Breeder Reactors (FBR) in the second stage; and thorium-based reactors in the third stage. The current share from water reactors is 4780 MWe from 20 reactors. The nuclear share including the imported Light Water Reactors (LWRs) under the safeguard (limited to $40 \mathrm{GWe}$ ) is targeted to be 63 GWe by 2032 . A scenario has been envisaged to enhance the nuclear share to 600 GWe in 2080-90 (figure 1). FBRs could be designed and deployed to burn minor actinides at appropriate time so that the radioactivity release from the waste would be insignificant (natural background level) within about 300 years. A large component of nuclear power capacity expansion has to be based on FBRs with closed fuel cycle.

The paper brings out the advantages of FBR and importance of developing closed nuclear fuel cycle for the large scale energy production, which is followed by its salient safety features. Further, the current status and future strategy of the FBR programme since the inception through $40 \mathrm{MWt} / 13$ MWe Fast Breeder Test Reactor (FBTR), will be highlighted. The challenges and achievements in science and technology of FBRs focusing on safety are described with particular reference to 500 MWe capacity Prototype Fast Breeder Reactor (PFBR), being commissioned at Kalpakkam. Indira Gandhi Centre for Atomic Research (IGCAR), is dedicated to the development of fast breeder reactor and associated fuel cycle science and technology. IGCAR is responsible for the design, $\mathrm{R} \& \mathrm{D}$, manufacturing technology and regulatory clearances. Bharatiya Nabhikiya Vidyut Nigam Limited (BHAVINI), a Government company is responsible for the construction and commissioning of the FBR projects. PFBR is its first project.

\section{Advantages of fast breeder reactors}

\subsection{Concept of breeding}

In a nuclear reactor, fissile materials, such as U233 or U235 or Pu239 are harnessed for producing energy through fission. U233 and Pu239 are produced by conversion of the fertile materials 
Th232 and U238, respectively. The ratio of fissile material produced and fissile material destroyed is termed as 'conversion ratio'. The conversion ratio, if greater than 1 , is called breeding ratio. If $\eta$ is the number of neutrons produced per neutron absorbed, the necessary condition for breeding is: $\eta=2+\mathrm{x}$, to account for one neutron for a new fission; one for a new conversion and $\mathrm{x}$ for leakages or parasitic captures. In view of its higher value of $\eta$ (above 2.45 for Pu239), FBR based on Pu fuel is the best among various spectrum reactor types to derive higher fissile material production that can be used to fuel another reactor. This is the fundamental characteristic of fast neutron reactors. Conversion ratio in a typical $1000 \mathrm{MWe}$ fast reactor core is $\sim 0.72$ and 0.6 for LWR of similar capacity. However, significant benefit is derived from the conversion in the blankets of the FBR core. The breeding ratio could be as high as 1.5 with the additional conversion in axial blankets in metal fuel. This is not the case with LWR; surrounding the core with a blanket does not significantly change its conversion ratio of 0.6 due to the low number of neutrons leaking out of the core. Hence, it is relatively easy to modulate the breeding ratio in the FBRs by enhancing the number of neutrons that are captured by changing the thickness of the blankets appropriately.

\subsection{Economic advantages}

In view of higher operating temperatures specifically in SFR $(>40 \%)$, it is possible to have high thermodynamic efficiency, compared to $30 \%$ in LWR. High thermodynamic efficiency has additional advantage of less thermal pollution to the environment. With the use of advanced materials for the fuel clad and wrapper, higher burn ups of 100-200 GWd/tonne can be achieved, compared to $55 \mathrm{GWd}$ /tonne for LWRs and $7 \mathrm{GWd} /$ tonne for PHWRs.

\subsection{Waste management}

Owing to the high level of neutron flux (10 times higher than that of a LWR) and to the ratios of capture cross sections to fission cross sections of major actinides more favourable in FBR by a factor of 10, it is easier in FBR to transmute the trans-uranium or minor actinides, such as Pu240, $\mathrm{Pu} 242$, Np237, americium, cesium, strontium, and curium. These elements are also primarily responsible for the decay heat that can cause repository temperature limits to be reached. The cesium and strontium can be stored separately for 200-300 years and plutonium, americium, and curium can be recycled for transmutation/fission. Hence, there is less impact on the fuel cycle (e.g., in fuel fabrication) and also large gains in repository space are possible. It is estimated that the ultimate accumulated long lived radioactive isotopes, which need to be disposed in repositories shall contribute less than $0.1 \%$ of all the fission products after multiple recycling in FBRs. Thus, the waste management burdens are reduced by about 200 times in terms of storage space (figure 2a) and less than 700 y timespan for the activity to become close to the background value (figure $2 b$ ).

\subsection{Advantages specific to Indian context}

India has limited indigenous uranium $(\sim 110 \mathrm{kt})$ and hence, FBRs are important due to its capability of efficient utilization of uranium. However, India has abundant thorium. The fast reactors also play important and essential role to exploit the thorium resources. Since thorium cannot straightway be used as nuclear fuel as it has no fissile isotopes, it can breed to give fissile isotopes (U233) by placing as blanket of $\mathrm{Pu}-\mathrm{U}$ fuelled fast reactors. However, premature introduction of thorium hampers the growth: increases the doubling time and hence, the introduction of thorium in the second stage would have to be done in a timely manner. Introduction of thorium 

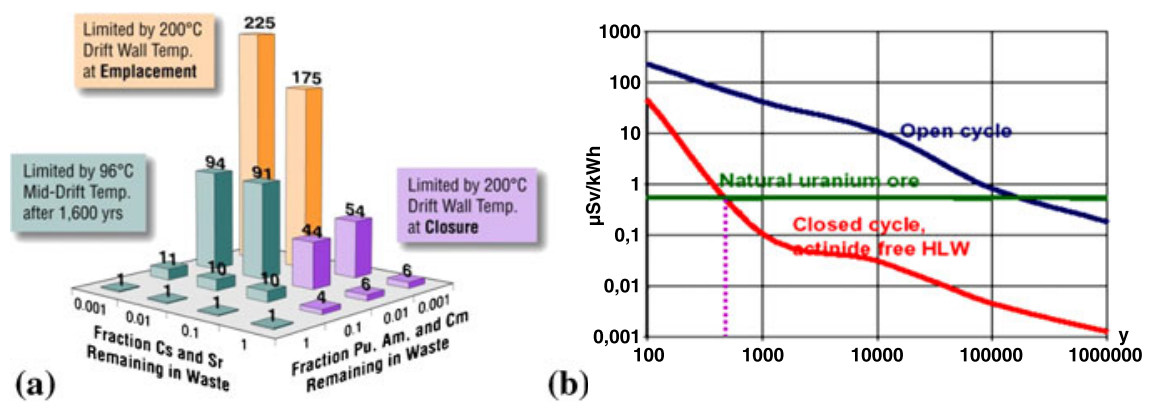

(b)

Figure 2. (a) Storage space requirements. (b) Benefits of closed fuel cycle.

without going to FBRs is extremely counterproductive, since the installed power capacity with thorium and plutonium being used together in thermal reactors will be insignificant given the India's requirements. The peak power level achieved briefly, with such premature use of thorium is very low (typically 36 GWe for a brief period) as compared to very high levels reachable through an optimum deployment strategy. Indian thorium is of the best quality available in the world and studies indicate that once the FBR capacity reaches about 220 GWe, thorium based fuel can be progressively introduced in the FBR in order to accelerate the third stage. Apart from above, the Sodium cooled Fast Reactors (SFR), in particular would provide critical liquid metal technology and high temperature design inputs for fusion and high temperature reactor systems, being pursued in the country. These systems can provide electricity at competitive costs over long periods.

In view of above advantages, FBRs are considered to be the most suitable and strong options for providing sustainable and environmentally acceptable energy systems and would be the mainstay of nuclear power programme in India. It is worth to remember the statements of Enrico Fermi, who demonstrated the breeding principle in 1946 itself: 'the people who will develop Liquid Metal based FSR technology will lead the world in the future'.

\section{General safety features of FBR}

FBRs have many inherent features, such as lower values of delayed neutron fraction $(\beta)$, shorter neutron generation time (1) and non-reactive core configuration, etc., which are claimed to be disadvantages for fast reactors. However, these do not pose truly any significant disadvantages. The benefits are derived from the fast and continuous reactivity feedback by the Doppler (enhanced neutron absorption cross sections due to temperature) and fuel expansion. In SFR, large margin between the normal operating sodium temperature and the boiling point of sodium can accommodate significant temperature rise in the event of mismatch between heat generation and heat removal. High thermal conductivity, low viscosity and large difference between the temperature of hot sodium at $820 \mathrm{~K}$ and ambient air at $310 \mathrm{~K}$, coupled with significant variation of sodium density with temperature, permit decay heat removal through natural convection mode. Further, in particular, pool type concept provides large thermal inertia and hence, more time to the operator to act in case of exigencies during reactor operation. Temperature and power coefficient of reactivity are negative. So in the event of disturbances in primary and secondary sodium flows or feed water flow, the reactor stabilizes to a new power level even without the corrective action of the operator. The potential initiators of coolant boiling are prevented by incorporating special 
design features. The temperature changes are measured accurately at the core outlet with very small time delay, employing fast response thermocouples so that at the right time, counter measures are possible. Many engineered safety features are introduced in the fast reactor system for ensuring the fuel cladding integrity, core coolability, reactor shutdown and decay heat removal systems with high reliability. A basic study reported in 1963 shows that the excursion-energy is small. The theory based on this evidence has been verified in an extensive reactor experiment, called 'SEFOR', USA.

These apart, there are only a few initiators which can introduce positive reactivities in FBR core viz. (i) gas entrainment, (ii) oil entry and (iii) coolant voiding. Regarding gas entrainment effects, though isolated gas bubbles of relatively small sizes distributed in the core may be possible scenario, they do not cause unacceptable reactivity variations. Further, it is also impossible to conceive a scenario, where a very large quantity of gas bubble (a few hundreds of litres) passing the core, that can cause significant reactivity change. Hence gas entrainment is not an issue in fast reactor safety. However, as a defense-in-depth, the design features (mechanical seals for the intermediate heat exchangers, porous plates attached with the reactor internals in the vicinity of sodium-free levels) are incorporated to avoid any possible gas entrainment mechanisms. Quantity of oil used especially for the pump bearing is minimized to the extent, that accidental oil leak is of not a great concern to the safety. Again here, as a defense-in-depth, oil catch pots are provided below the oil tanks to prevent the oil fall into the reactor sodium. This apart, oil free bearings (ferro-magnet bearings) are conceived for the future design of pumps to completely eliminate the oil entry issue.

\section{Fast reactor programme in India}

The targets and strategies of SFR development are illustrated comprehensively in figure 3. FBR programme was started by constructing a loop type FBTR, which is in operation since 1985.

- Indigenous Design \& Construction

- Comprehensiveness in development of Design, R\&D and Construction

- High Emphasis on Scientific Breakthroughs

- Synthesis of Operating Experiences

- Synthesis of Emerging Concepts (Ex.GENIV)

- Focus on National \& International Collaborations

- Emphasis on high quality human resources

- Creation of environment for enabling innovations

- Marching towards world leadership by 2025
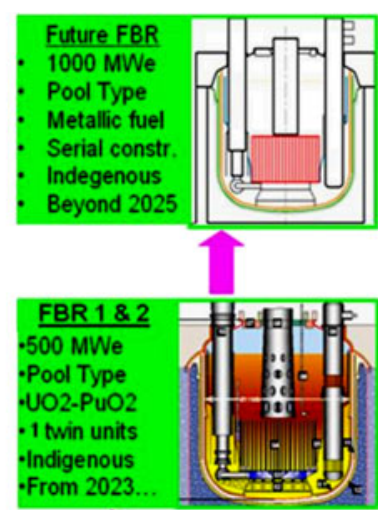

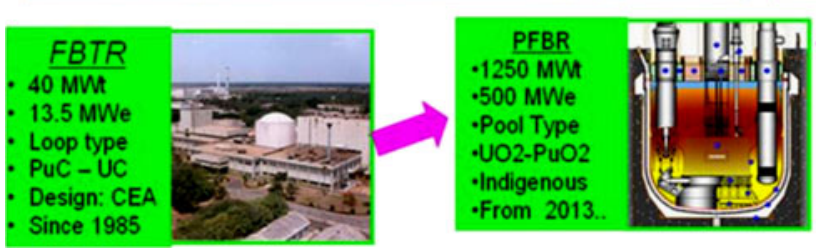

Figure 3. Indian fast reactor programme. 
With the PHWR programme well on its growth path and having established comprehensive expertise in SFR Technology through successful operation of FBTR over 27 years, India is now on a robust pathway for development of SFR- based second stage of the programme with PFBR, launched in October 2003. PFBR is undergoing stage commissioning tests and scheduled for completion in 2013. It is envisaged that additional units of 500 MWe, MOX fuel based on twin unit with the improved economics and enhanced safety over PFBR will be built before launching metal fuel FBRs (1000 MWe capacity). In view of high breeding ratio, the nuclear power could grow rapidly. However, complete realization of SFR technology involves many challenges in science, design, safety and technology, especially in fuels and core structural materials and instrumentation aspects.

\subsection{FBTR and its current status}

FBTR is a sodium cooled, loop type fast reactor, fuelled with a unique high $\mathrm{Pu}$ mixed carbide fuel. It has two primary and two secondary sodium loops. Each secondary loop has two once-through, serpentine type Steam Generators (SG). All the four SG modules are connected to a common steam-water circuit having a Turbo-Generator (TG) and a $100 \%$ steam Dump Condenser (DC). The first criticality was achieved in October 1985 with a small core of 22 fuel subassemblies (SA) of MK-I composition $(70 \% \mathrm{PuC}+30 \% \mathrm{UC})$, with a design power of 10.6 MWt and peak linear heat rating (LHR) of $250 \mathrm{~W} / \mathrm{cm}$. Progressively the core was expanded by adding SA at peripheral locations. Carbide fuel of MK-II composition (55\% PuC $+45 \% \mathrm{UC})$ was inducted in the peripheral locations in 1996. TG was synchronized to the grid for the first time in July 1997. LHR of MK-I fuel was increased to $400 \mathrm{~W} / \mathrm{cm}$ in 2002. Eight high Pu MOX fuel SA $\left(44 \% \mathrm{PuO}_{2}\right)$ were loaded in the core periphery in 2006 . The reactor has so far been operated up to a power level of $20 \mathrm{MWt}$. PFBR test fuel subsequently has been irradiated up to a peak burnup of $112 \mathrm{MWd} / \mathrm{t}$. The indigenously developed unique Pu-rich mixed carbide fuel has performed extremely well crossing a burn-up of 165,000 MWd/t. One of the important achievements is closing of the fuel cycle of FBTR. The FBTR fuel discharged at $155,000 \mathrm{MWd} / \mathrm{t}$ has been successfully reprocessed and refabricated. This is the first time that the Pu-rich carbide fuel has been reprocessed anywhere in the world. Towards designing and building future metallic fuelled test reactors, irradiation of metallic fuel pins is in progress. Further, the reactor life is to be extended by 20 years to serve as an irradiation facility for the development of fuels and structural materials. Apart from these, FBTR has given high confident for the successful construction, commissioning and operation of SFRs.

\subsection{PFBR and its current status}

PFBR is a pool type reactor with 2 primary and 2 secondary loops with 4 steam generators per loop. Pool and loop type concepts were studied comprehensively considering the associated merits and demerits, specific to medium size reactors like PFBR. It is concluded that pool type shall be our choice. The governing parameters meriting the choice are large thermal inertia that permits severe thermal transients, higher structural reliability of main vessel in view of no penetrations in sodium boundary and much reduced primary sodium piping. It is also our perception that the complexities that are associated with the pool type of reactor such as thermal hydraulics, manufacturing and handling of over dimensioned thin vessels with stringent tolerances can be successfully met by the designers and our industry. Subsequently, it has been confirmed from detailed analysis backed up with experimental validation and extensive 1:1 technology 
development exercise. The overall flow diagram comprising primary circuit housed in reactor assembly, secondary sodium circuit and balance of plant (BoP) is shown in figure 4 . The nuclear heat generated in the core is removed by circulating sodium from cold pool at $670 \mathrm{~K}$ to the hot pool at $820 \mathrm{~K}$. The sodium from hot pool after transporting its heat to four intermediate heat exchangers (IHX) mixes with the cold pool. The circulation of sodium from cold pool to hot pool is maintained by two primary sodium pumps and the flow of sodium through IHX is driven by a level difference ( $1.5 \mathrm{~m}$ of sodium) between the hot and cold pools. The heat from IHX is in turn transported to eight SG by sodium flowing in the secondary circuit. Steam produced in SG is supplied to turbo-generator. In the reactor assembly, the main vessel houses the entire primary sodium circuit including core. The inner vessel separates the hot and cold sodium pools. The reactor core consists of 1757 subassemblies including 181 fuel subassemblies. The control plug, positioned just above the core, houses mainly 12 absorber rod drive mechanisms. The top shield supports the primary sodium pumps, IHX, control plug and fuel handling systems. PFBR uses mixed oxide (MOX) fuel with depleted and natural uranium and approximately $25 \%$ Pu oxide. For the core components, $20 \%$ cold worked D9 material (15\% Cr- $15 \% \mathrm{Ni}$ with $\mathrm{Ti}$ and $\mathrm{Mo}$ ) is used to have better irradiation resistance. Austenitic stainless steel type $316 \mathrm{LN}$ is the main structural material for the out-of-core components and modified 9Cr-1Mo (Grade 91) is chosen for SG. The reactor is designed for a plant life of $40 \mathrm{y}$ with a load factor of $75 \%$.

The construction of PFBR is at the advance stage of completion. The dummy core loading is nearing completion (figure 5). The reactor is being commissioned in steps towards making operational in 2013. The nuclear steam supply system components are being manufactured successfully by the Indian Industries. Manufacture of all reactor assembly components, such as safety vessel, main vessel, inner vessel, thermal baffles, grid plate, primary sodium pipes, roof slab, large and small rotatable plugs, IHX, pumps, fuel transfer machines were completed meeting the stringent tolerance requirements. These components were erected successfully meeting all the specified erection tolerances (figure 6).

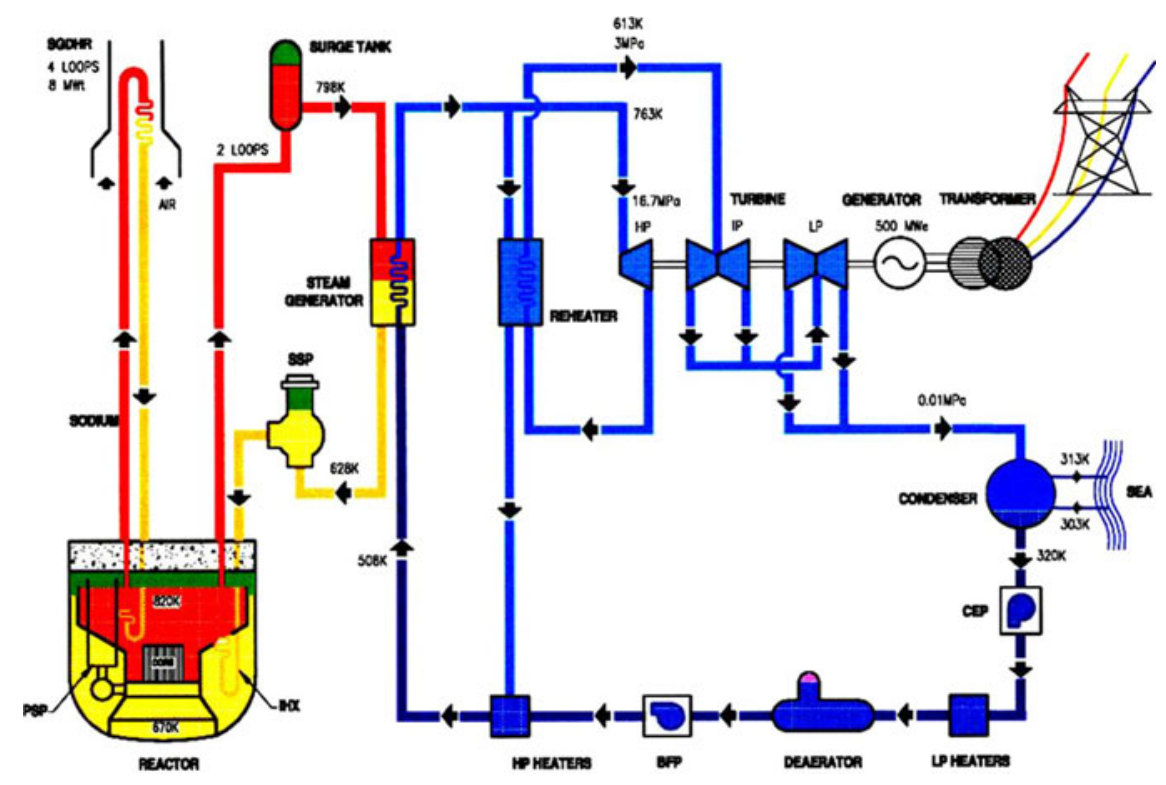

Figure 4. PFBR heat transport flowsheet. 


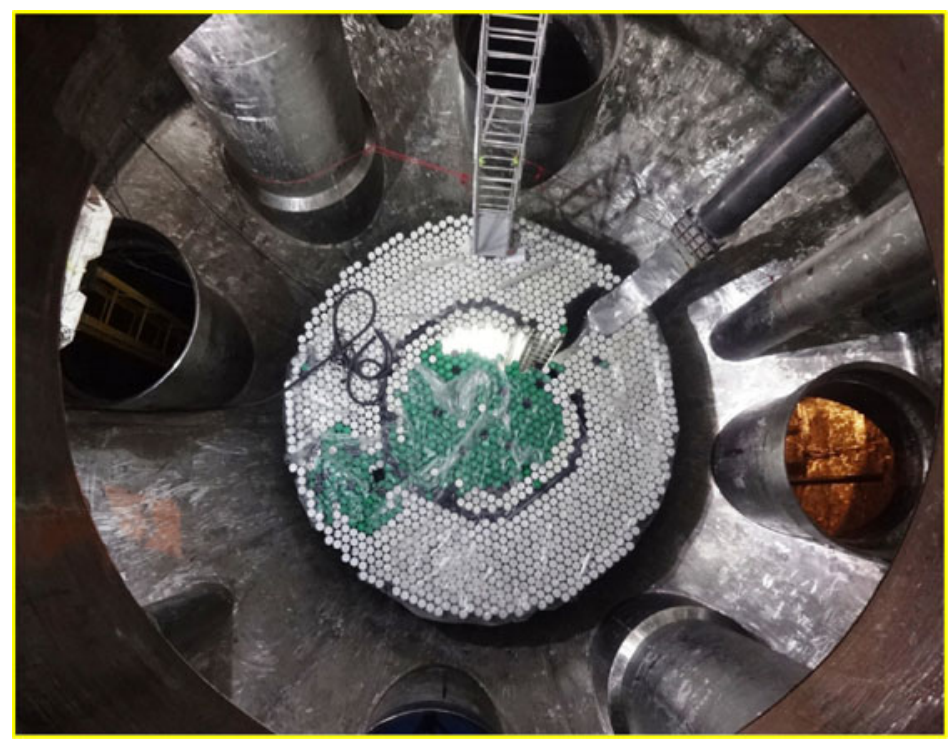

Figure 5. Dummy core loading.

\subsection{Design and development of future SFRs}

Comprehensive assessment of various issues towards commercialization of SFR system indicates that the most important one relates to its capital cost. The current designs are costly, mainly due to high capital cost varying from $20 \%$ to $60 \%$ as compared to well-established water reactors. Recent studies have identified various high impact factors governing capital cost. R\&D efforts should be enhanced significantly to minimize the capital cost, through which it is possible to demonstrate that the SFR systems would be economically competitive as compared to thermal reactor systems or even fossil power systems. Russian study demonstrates that the specific capital costs of current and evolving designs such as Japanese SFR (JSFR), Russian BN-1800 and Indian Fast Breeder Reactors are comparable to reference LWR and further, the steel consumption
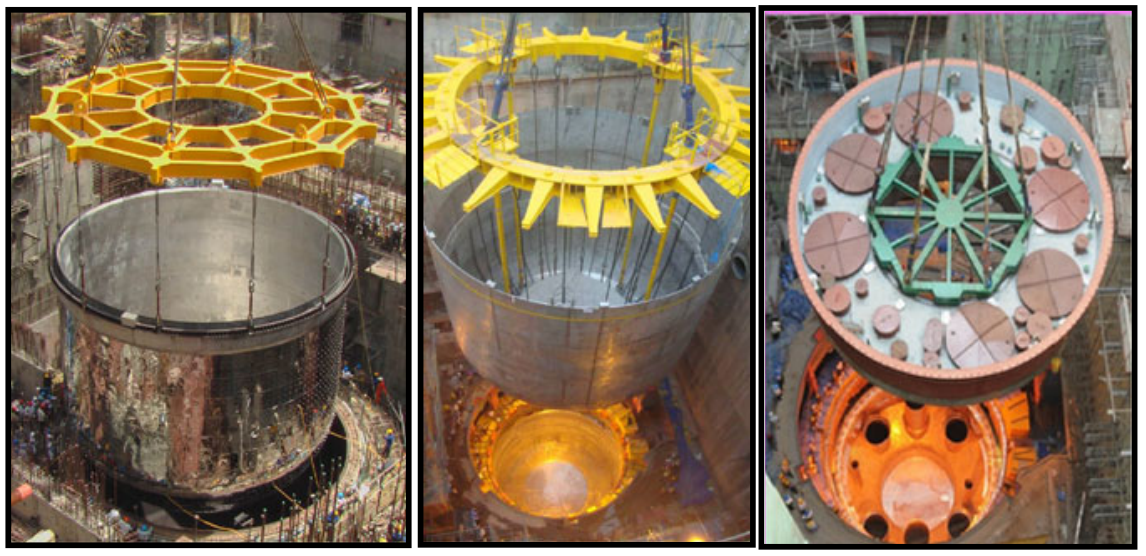

Figure 6. Erection sequence of large size reactor assembly components. 


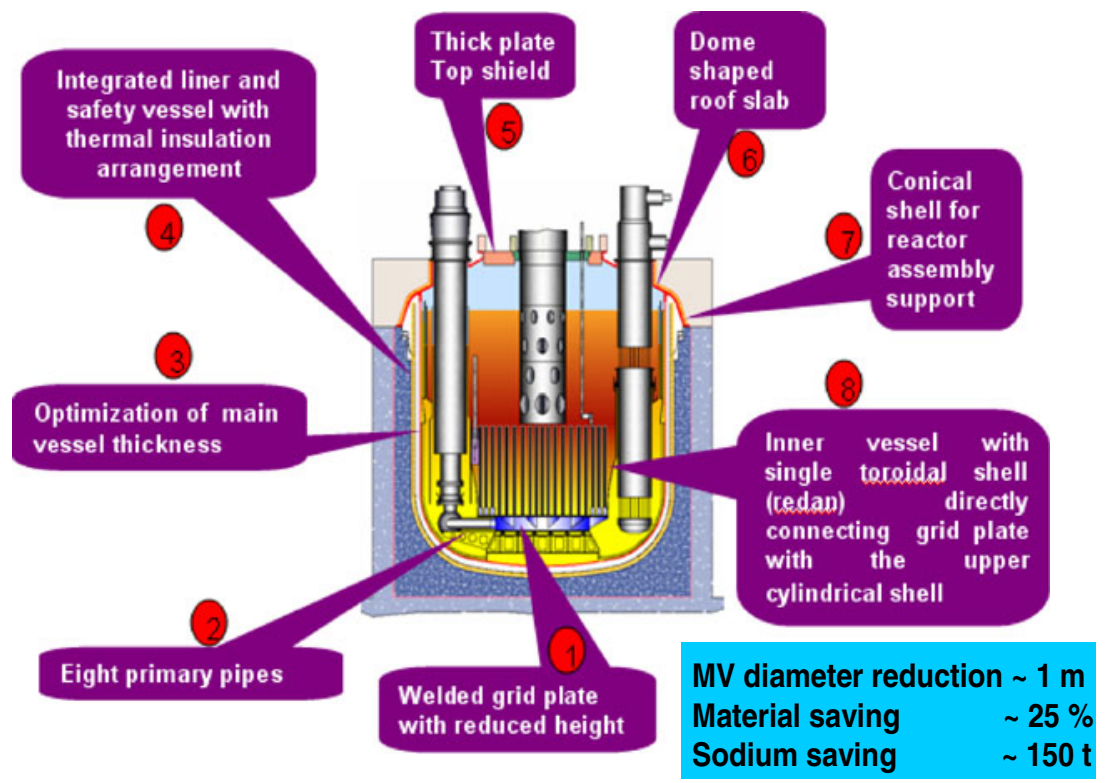

Figure 7. Innovative features of reactor assembly of future SFR.

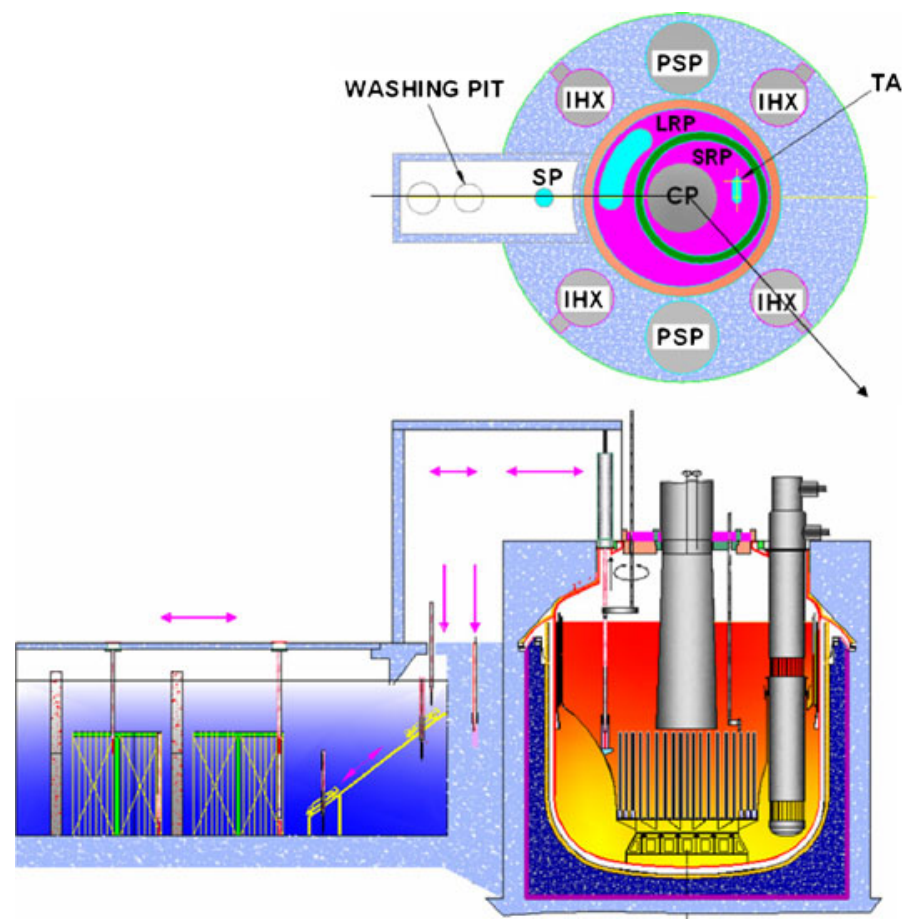

Figure 8. Simplified fuel handling scheme. 
and in-turn capital cost can be brought down significantly in the future designs with enhanced R\&D inputs.

An immediate step followed by PFBR is to construct two more 500 MWe SFR by adopting twin unit concept $(2 \times 500 \mathrm{MWe})$ introducing new concepts to improve economy as well as to enhance safety. The twin unit will be constructed at Kalpakkam adjacent to PFBR. Towards improving economy, apart from adopting twin unit concept, (i) optimum shielding, (ii) use of less expensive $304 \mathrm{LN} /$ ferritic steels in place of $316 \mathrm{LN}$ for colder piping, (iii) three SG modules per loop with increased tube length of $30 \mathrm{~m}$ (PFBR has 4 modules per loop with $23 \mathrm{~m}$ length), (iv) 60 years design life with $85 \%$ load factors, (v) reduced construction time (5 y) with pre-project action on manufacturing of long delivery mechanical components of nuclear steam supply system, and (vi) enhanced burn up (up to $200 \mathrm{GWd} / \mathrm{t}$ to be achieved in stages) are being considered.

The reactor assembly has been revised significantly based on PFBR construction experience. The improved design concepts under consideration are (figure 7): (1) compact and symmetric welded grid plate without fuel transfer post, (2) eight numbers of smaller diameter seamless primary pipes, (3) reduced thickness for main vessel with realistic tolerances, (4) safety vessel made of carbon steel integrated with reactor vault liner, (5) thick plate rotatable plugs, (6) dome shaped thick plate roof slab, (7) conical skirt support which is under compression, and (8) inner vessel with single curved redan integrated with fuel transfer post. Further, control plug integrated with small rotatable plug, safety vessel embedded with reactor vault and simplified fuel handling scheme with elimination of inclined fuel transfer machine (figure 8) are studied. The improved

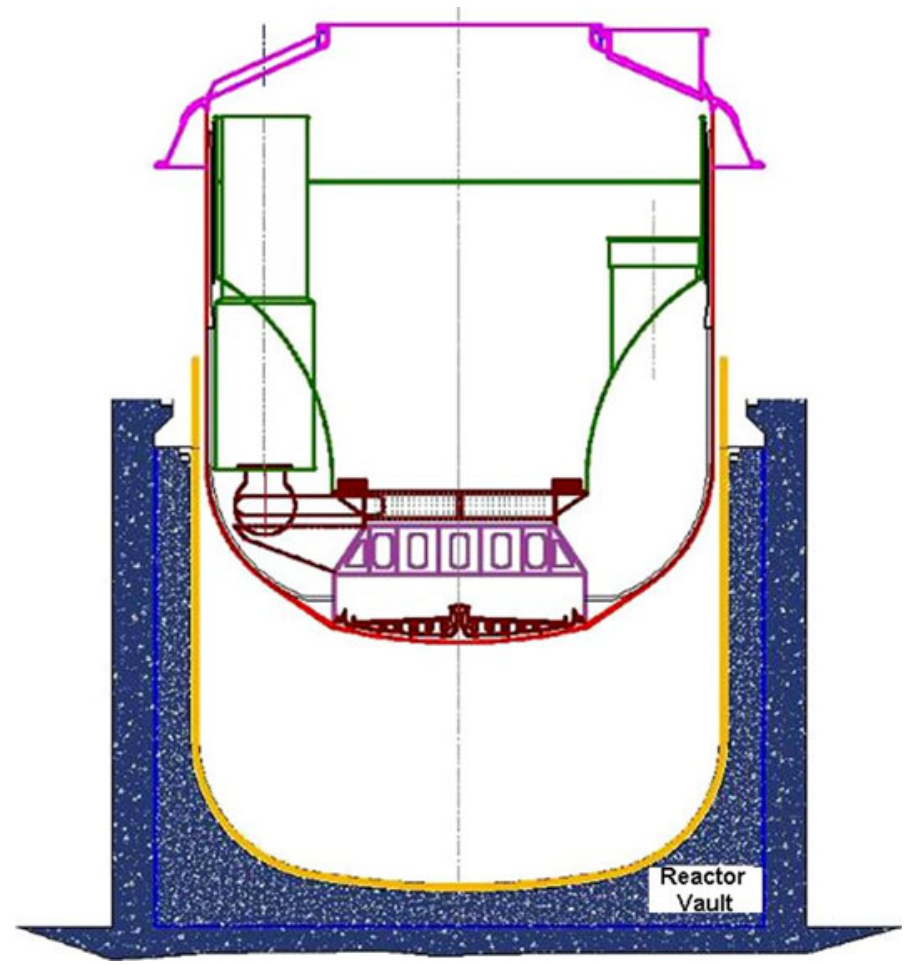

Figure 9. Erection of reactor assembly. 
design concepts have indicated significant economic advantages: material inventory reduction $\sim 25 \%$ and simplified fuel handling scheme. In view of reduced size (12.1 m diameter) and lower weight $(<450 \mathrm{t})$ of reactor assembly, it is possible to manufacture the reactor assembly at the Industry in parallel to the civil construction of the plant at site and subsequently inserted into the reactor vault (figure 9). This would reduce the construction time significantly.

\section{Realization of fast breeder reactors: Challenges}

\subsection{Design challenges}

Design calls complete understanding of unique fuel and structural materials working under high temperature, sodium, irradiation environments over the long reactor life, sodium chemistry, aerosol behaviour, sodium fire and sodium water reactions, special sensors for sodium applications (detection of water leaks in steam generator, sodium leaks, purity measurements, level detectors), thermal hydraulics and structural mechanics (turbulences, instabilities, gas entrainments, thermal striping, stratifications, ratcheting, etc.). Various failure modes, which form the basis for the structural design, are depicted in figure 10. The design of components operating at high temperature $(820 \mathrm{~K})$ and long life (40-60 years) should address these failure modes comprehensively. Further, seismic analysis of interconnected buildings resting on the common base raft and seismic design of thin walled vessels, pumps and absorber rod mechanisms are quite challenging task in the design. Sodium, because of its opaqueness poses problems for in-service inspection of reactor internals within sodium.

\subsection{Technological challenges}

Technology of SFRs demands manufacturing capability of large dimensioned welded thin shell structures made of austenitic stainless steel petals with close tolerances ( $\sim$ thickness),

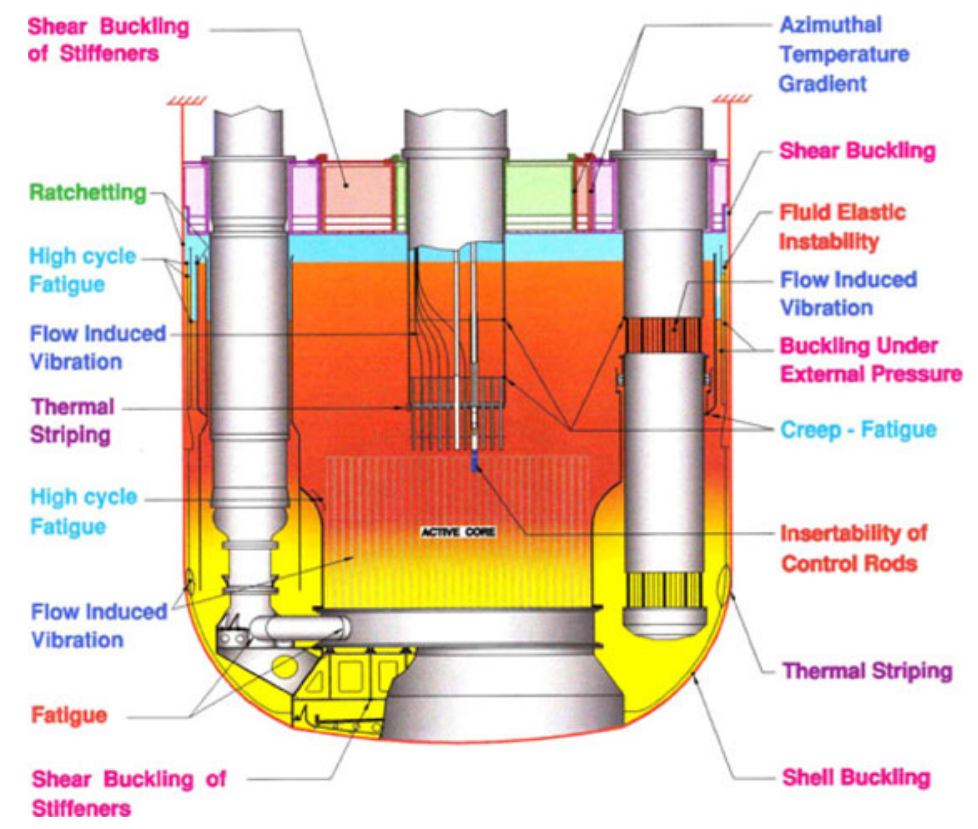

Figure 10. Failure modes for structural design. 


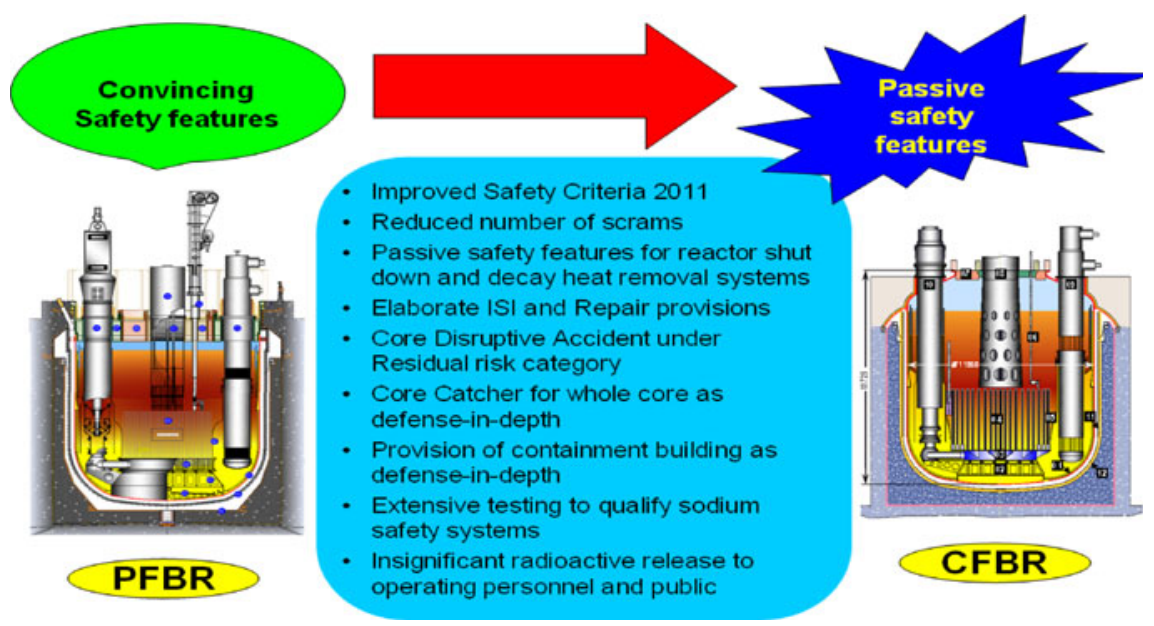

Figure 11. Enhanced safety features of future SFRs.

machining of large dimensioned and tall slender components with stringent tolerances (grid plate, absorber rod drive and component handling systems), fabrication of large size box structures with controlled distortions, reliable tube to tubesheet butt welds of steam generator, hard facing technology with special materials, development of inflatable seals and large size bearings. Further, development of large size bearings, inflatable seals and high temperature fission chambers could be achieved only through detailed technology development exercises.

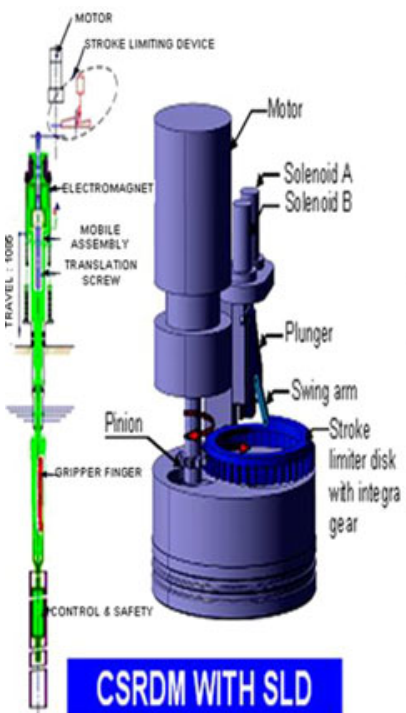

(a)

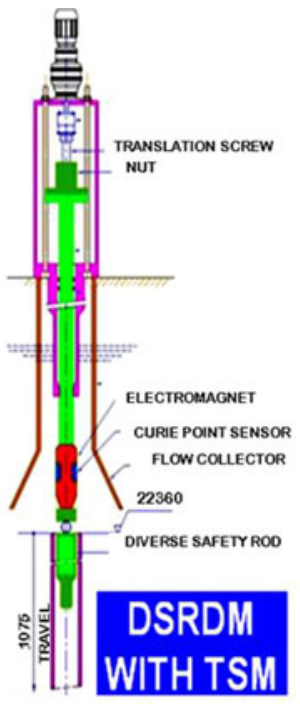

(b)

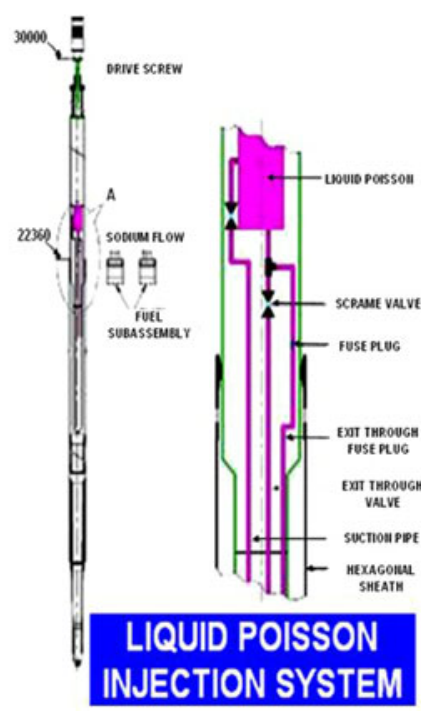

(c)

Figure 12. Passive shutdown systems conceived for future SFRs. 


\subsection{Achieving enhanced safety}

It is important to introduce novel features to enhance the reliability of safety related components compared to PFBR, which is highlighted in figure 11. The reliability of shutdown systems has to be increased at least one order higher compared to shutdown systems of PFBR, by introducing (1) reliable drop time measurement for diverse shutdown system through multiple techniques (Eddy Current, Kalman Filter \& Acoustics), (2) stroke limiting device in control and shutdown rod drive mechanisms to minimise probability of occurrence of inadvertent withdrawal of rods (figure 12a), (3) temperature sensitive electromagnet in diverse shutdown systems to minimize failure of shutdown system due to instrumentation failure (figure 12b) and, (4) liquid poisson injection system as ultimate shutdown systems (figure 12c). For achieving reliable decay heat removal function, 3 safety grade decay heat removal (SGDHR) system circuits with forced cooling (2/3 of heat removal under natural convection) and 3 SGDHR circuits with natural convection cooling each with a power removal capacity of $6 \mathrm{MWt}$ are conceived.

\section{Highlights of R\&D carried out for PFBR}

\subsection{Core thermal hydraulics studies}

The core is monitored by functionally diverse sensors, viz. neutron detectors, temperature monitors. These parameters provide protection against transient over power, transient under cooling and anomalous reactivity addition events. Monitoring of sodium temperature is done by providing 3 fast response thermocouples mounted on the central canal plug to monitor central fuel subassembly sodium outlet temperature. Detailed thermal hydraulics analysis is carried out (1) to obtain an optimization of number of flow zones, since more number results in complex administrative control for subassembly (SA) loading and lesser number calls for higher pump capacity (figure 13), and (2) for deriving accurate hot spot temperatures in fuel, clad and coolant (figure 14). CFD analysis is carried out to determine flow and temperature distributions below the core cover plate to quantify the dilution in the measured sodium outlet temperatures, due to manufacturing/erection tolerances and thermal/irradiation induced bowing of the subassemblies (figure 15).

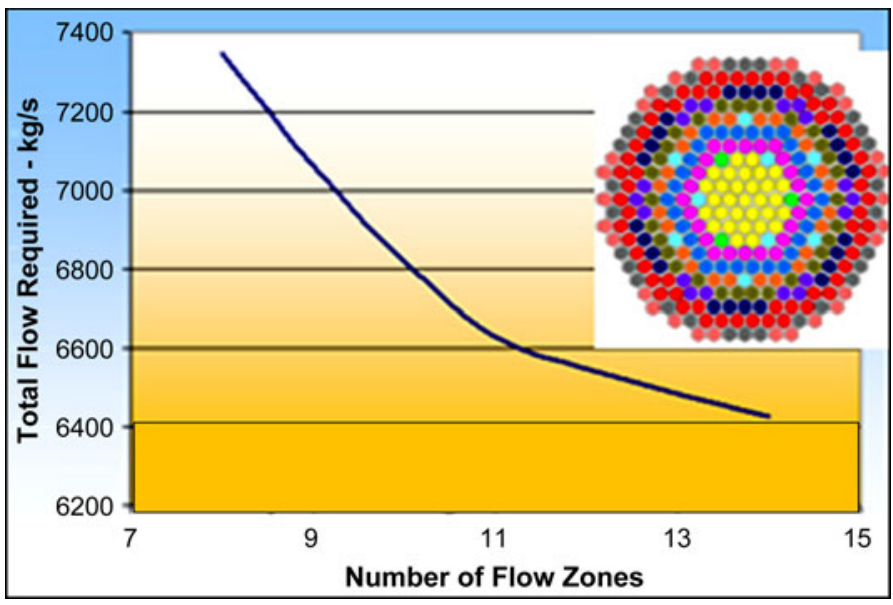

Figure 13. Finalizing flow zones. 

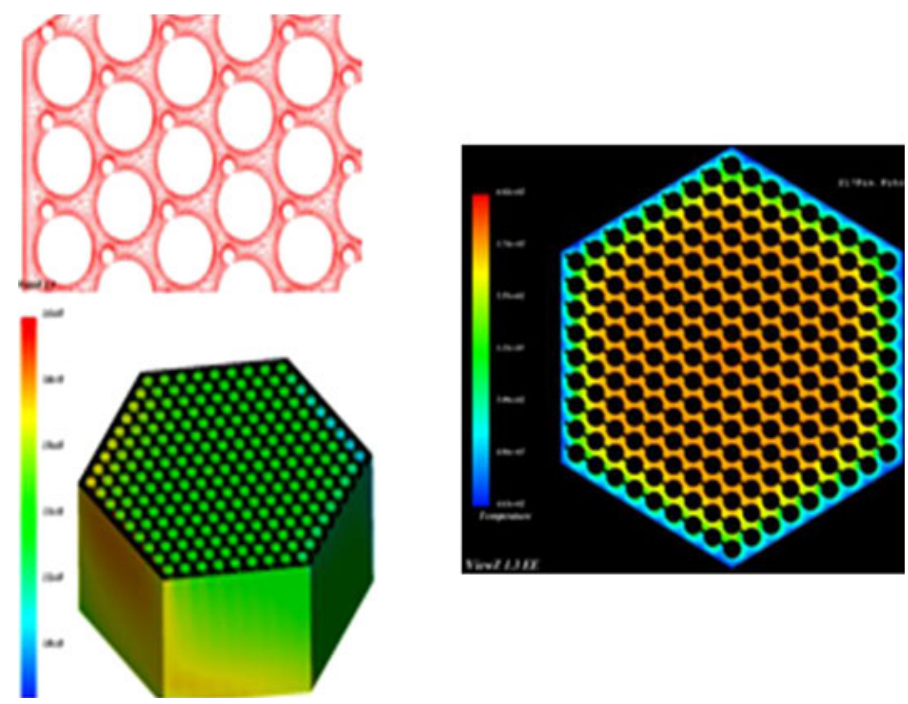

Figure 14. Temperatures within SA.

\subsection{Testing of mechanisms in sodium}

In order to ensure safe and reliable operation of mechanisms operating in sodium, the components, viz. under sodium scanner (USS), safety grade decay heat removal system (SGDHR), control and safety rod drive mechanism (CSRDM), diverse safety rod drive mechanism (DSRDM), transfer arm (TA) and inclined fuel transfer machine (IFTM) are tested in sodium at their operating temperature ranges (figure 16).

\subsection{Performance of safety grade decay heat removal (SGDHR)}

Even after reactor shutdown, core continues to generate decay heat (about $1.5 \%$ and $0.7 \%$ of nominal power respectively $1 \mathrm{~h}$ and $1 \mathrm{~d}$ after reactor shutdown). If off-site power is available, decay heat removal is through the normal heat transport system, i.e., through steam generators and steam-water system. The system is known as Operation Grade Decay Heat Removal System. In case of loss of off-site power, loss of secondary circuit or steam water circuits, the decay heat is removed through 4 independent Safety Grade Decay Heat Removal (SGDHR) loops. The SGDHR operation is robust in even most demanding envisaged condition of accident. Each loop consists of a Decay Heat Exchanger (DHX) of capacity $8 \mathrm{MWt}$ with tube side linked to a intermediate sodium circuit which is connected to sodium-air heat exchanger (AHX). The ultimate heat sink is air. Figure 17 shows one typical SGDHR loop. The layout of SGDHR circuit ensures decay heat removal by natural convection in primary sodium, intermediate sodium and air side. Two dampers of diverse design are provided at inlet and outlet of AHX and two diverse designs of DHX and AHX are provided to enhance reliability. Diesel and battery power is also provided to drive the primary pumps at $15 \%$ of the speed for conditions of off-site power failure and station blackout conditions as a defense in depth approach. Reliability analysis is carried out by fault-tree method including common cause of failure between redundant non-diverse components/systems. Hot sodium ensuing out of the core $\left(\sim 550^{\circ} \mathrm{C}\right)$ reaches top surface of the pool and enters the DHX, gets cooled to $\sim 350^{\circ} \mathrm{C}$ and leaves the DHX at the bottom of the hot 


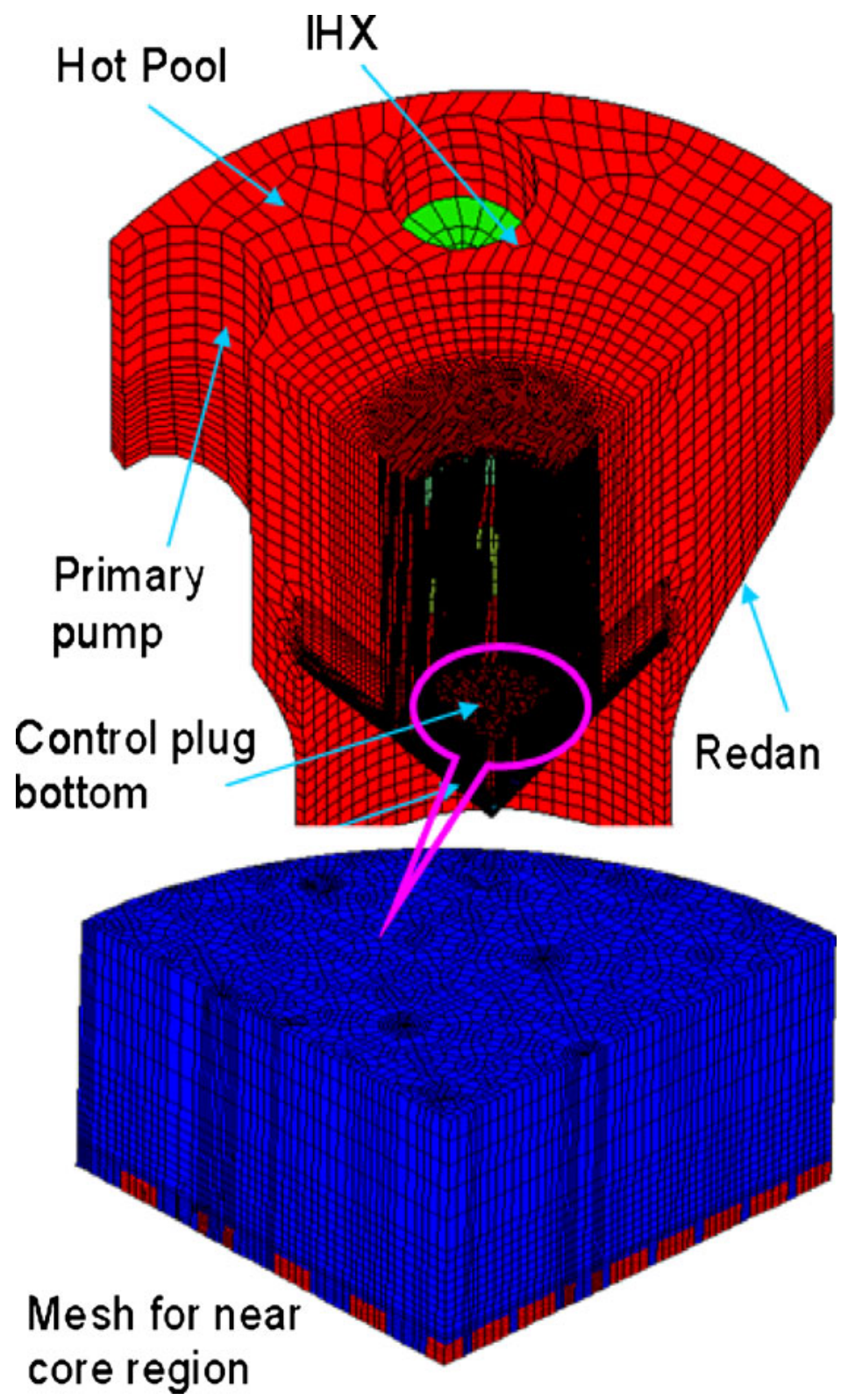

Figure 15. Core temperatures (CFD).

pool. This cold sodium has a strong potential to remove significant amount of the decay heat while it flows over the outer surfaces of the fuel subassemblies. The heat removal capability of this flow, known as inter wrapper flow, has been established based on a combined 'system levelmultidimensional' thermal hydraulic model (figure 17). Based on this study, it is found that the temperature limits of the core are satisfactorily met even under strong cyclones through pure natural convection itself. 

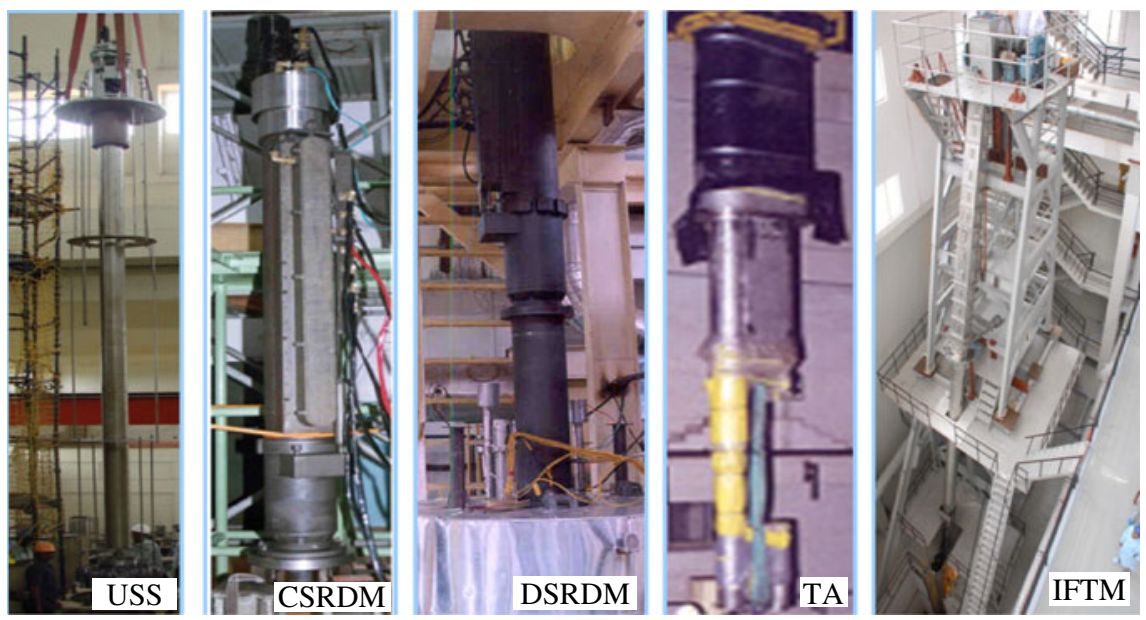

Figure 16. Mechanisms tested in sodium at high temperatures.

\subsection{Safety against external events}

A large number of external events can affect the plant (figure 18). Consideration is given to the external events like, floods, earthquakes, cyclones, lightening and various man made events. Kalpakkam is also a relatively isolated place and there is no significant industrial activity around it, which may affect the reactor through incidents like fires and explosions. Further, the nearest airport is about $50 \mathrm{~km}$ away and the air corridor having significant air traffic does not pass over the site. Thus the probability of an air crash at the reactor is extremely low. A low trajectory

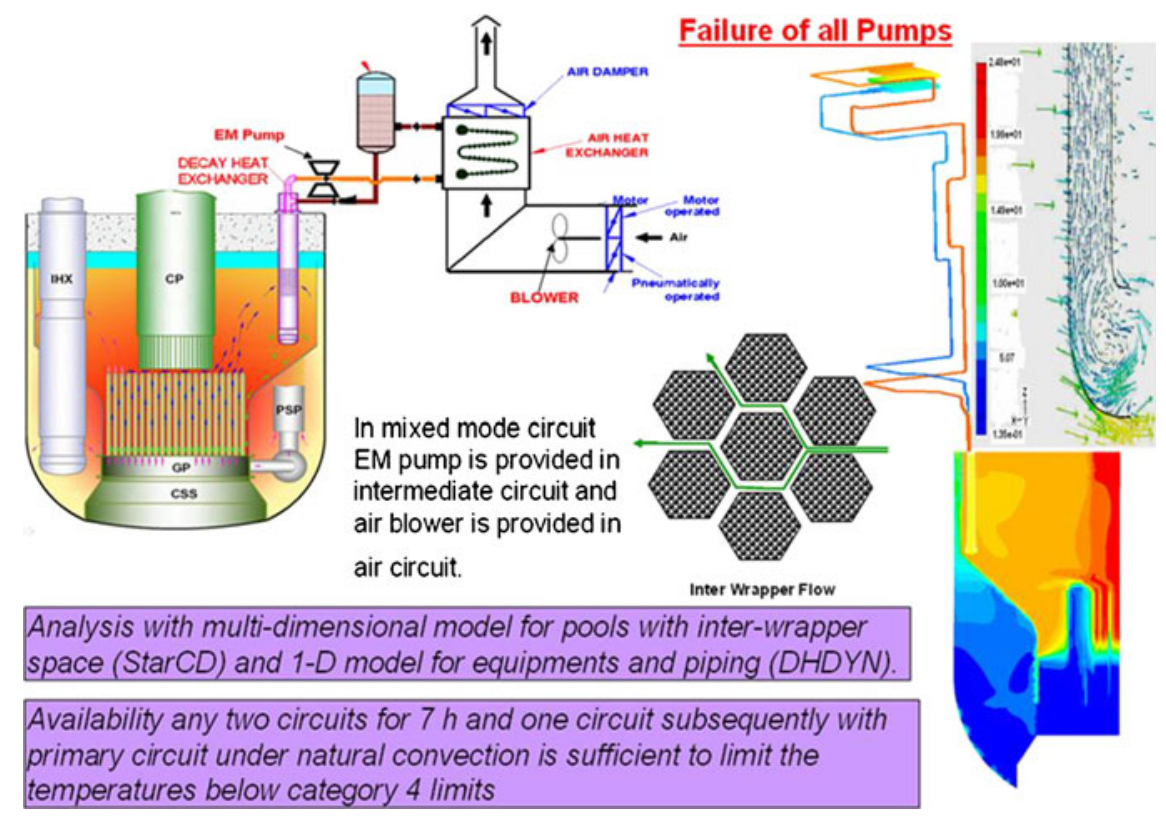

Figure 17. Ensuring the smooth function of SGDHR system under severe cyclone conditions. 


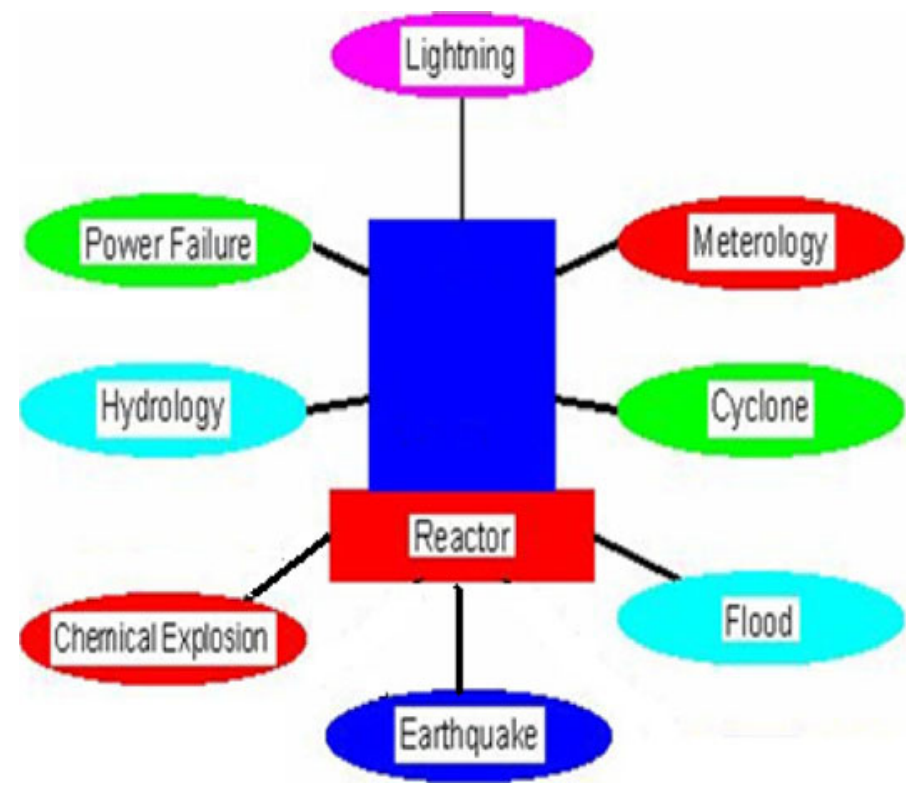

Figure 18. External events considered for design.

turbine missile is considered in the plant layout of safety structures. By choosing radial location of turbine, it is ensured that the missile does not hit the safety structures. Kalpakkam site is in a seismically stable region. It has been established for this site that for SSE design basis peak ground horizontal acceleration is $0.156 \mathrm{~g}$ and vertical acceleration is $0.104 \mathrm{~g}$. The peak ground accelerations for OBE are $0.078 \mathrm{~g}$ and $0.052 \mathrm{~g}$. Structures important to the operation of the plant are designed according to the state of the art methods for withstanding consequences of earthquake. Nuclear steam supply system remains functional after an OBE. Under SSE, safety related components are designed such that the plant is shutdown safely and remains in shutdown state subsequently. Kalpakkam site being on the east coast, is prone to severe cyclones. Consequently, a detailed analysis has been carried out for arriving at Design Basis Flood Level (DBFL). For safety related structure, DBFL has been determined based on return period of 1000 years.

Seismic events impose major loading on the reactor structures, systems, components and equipments. The geometrical characteristics, particularly large size thin walled shell structures, high sodium mass distributions and boundary conditions enhance the effects of seismic events. The main vessel carries about 2500 tons contributed mainly by sodium (1150 tons), core (550 tons) and self weight of main vessel and its internals. The weight of top shield along with the components supported by it is about 1200 tons. Thus the reactor assembly, which is hanging from the top support, weighs approximately 3700 tons. Further, there exists relatively thin annulus of liquid between: (1) inner vessel to inner baffle, (2) inner baffle to outer baffle and (3) outer baffle to main vessel. The annulus gap to diameter ratio is $w / D \sim 1 / 100$, which contributes significant added masses to the adjacent shells. The existence of large free fluid surfaces is the source of sloshing phenomena during normal operation as well as seismic events. Due to these features, the reactor assembly components have their fundamental natural frequencies less than $10 \mathrm{~Hz}$, over which seismic floor responses show maximum dynamic amplifications. Hence, seismic events impose high dynamic forces, even though mechanical loadings (self weight and hydrostatic pressure heads) are low under normal operating conditions. For large size thin walled 
shells $(\mathrm{D} / \mathrm{h}>500)$, buckling is the dominant failure mode under dynamic forces developed during seismic events.

The reactor safety is ensured by respecting the following design criteria: (1) reactivity insertion because of core compaction due to horizontal displacements and relative vertical displacements between the absorber rod and fuel subassembly, should be less than $0.5 \$$, (2) it should be possible to insert absorber rods during SSE, (3) the drop time of absorber rods should be less than $1 \mathrm{~s}$, (4) primary pumps should not seize, (5) sodium ejection to the reactor containment building (RCB) through the top shield penetrations is to be prevented, (6) the stresses at the components should be less than the allowable values as per the RCC-MR (French Code for the design of fast reactors) to ensure that there is no risk of buckling and loss of structural integrity. In order to demonstrate that the reactor assembly components meet the above mentioned safety criteria, advanced numerical and experimental investigations are carried out. Typical results are depicted in figure 19.

\subsection{Sodium safety}

Use of large amount of sodium in the primary coolant system is advantageous from the standpoint of safety, because of high heat capacity of sodium and natural circulation flow. In spite of the above positive features, sodium leaks can not be completely ruled out. There were 32 leaks in Phenix and 27 leaks in BN 600 reported, but they have not affected the plant availability seriously. Safe disposition of huge amounts of radioactive sodium during decommissioning stage would call for high investment and operational cost and complex technologies. Also, there are a few specific structural mechanics problems related to sodium, viz. thermal striping and thermal fluctuations, which severely affect the structural integrity of adjoining structures. These are the critical issues, responsible for slowing down of SFR development and forcing the researchers to

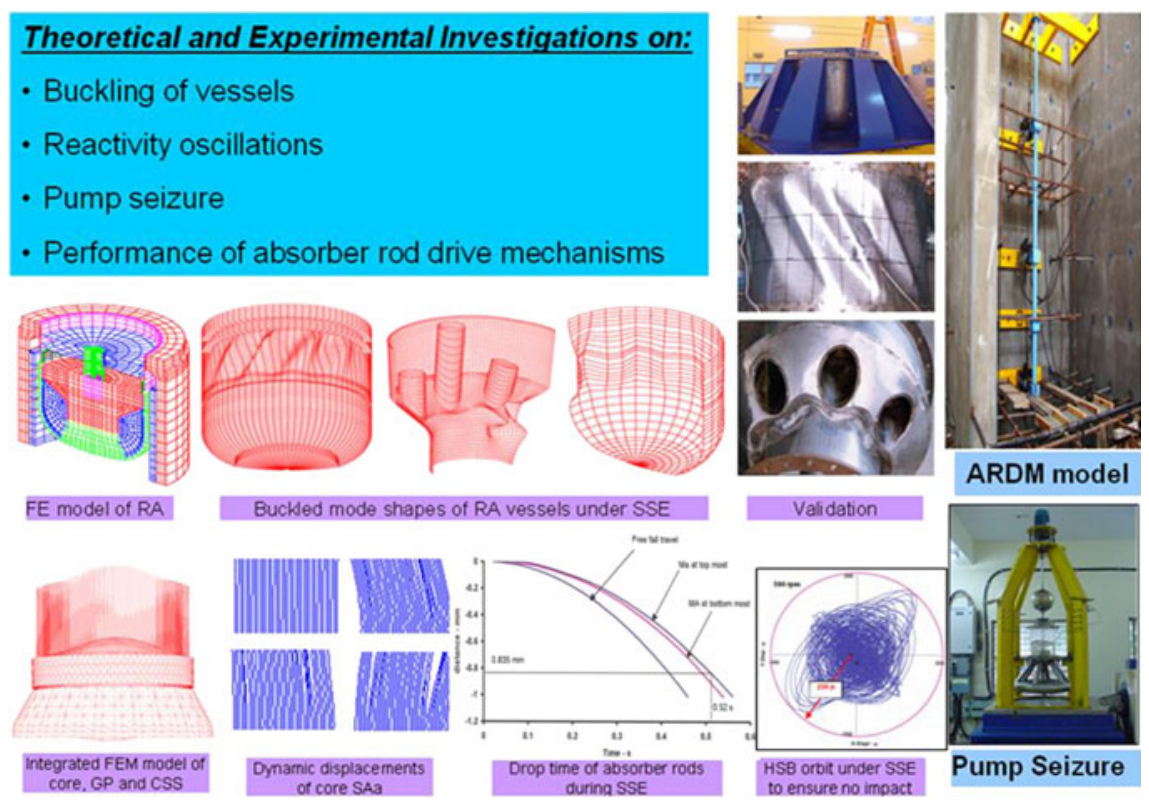

Figure 19. Investigations to comply seismic design criteria. 
study alternate coolants, such as gases (helium and $\mathrm{CO}_{2}$ ), and alternative liquid metals (lead and lead-bismuth). Despite these facts, the problems have been overcome through suitable design measures, for e.g., the quantity of sodium used in the reactor is optimized by choosing possibly minimum size of reactor and heat removal systems through innovative design concepts. Another major limitation of sodium is its opaqueness, which poses challenges for the in-service inspection of reactor assembly internals. In this regards, indigenous development of vibration measurements systems and under sodium viewing play key role. The under-sodium scanners are essential for the successful fuel handling operation without having any risk of damage of fuels

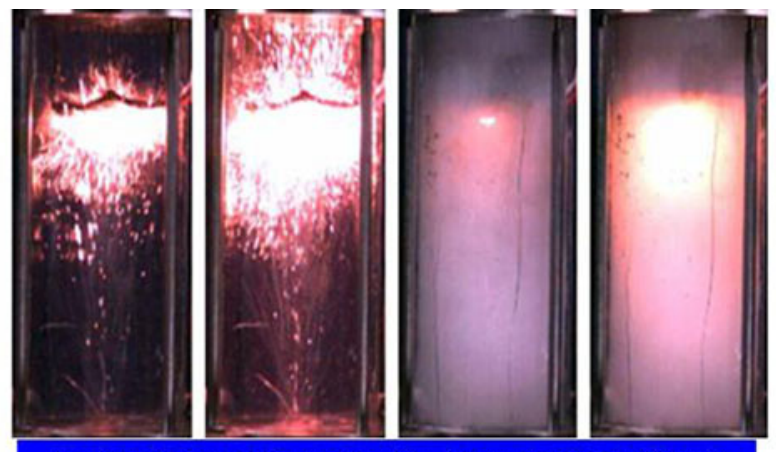

$\mathrm{Na}$ fire followed by cable fire (Top shield platform)

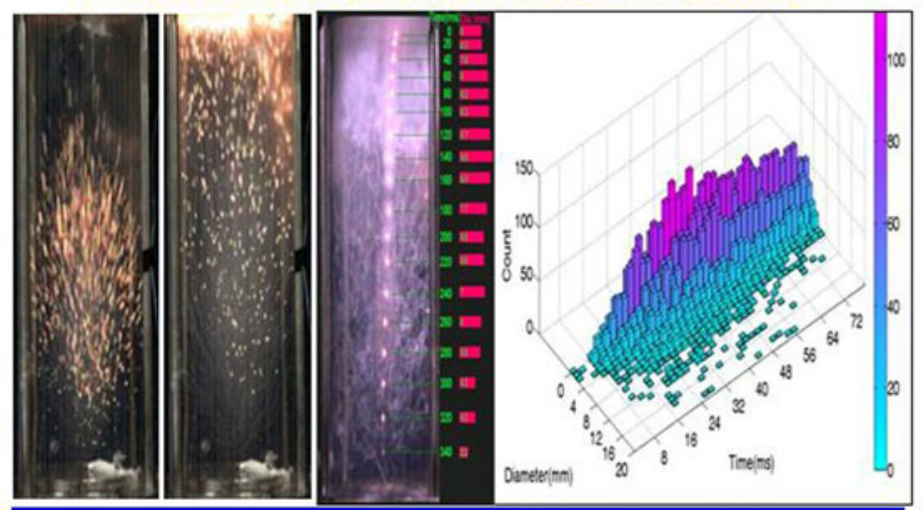

Na spray fire scenarios and burning charcteristics
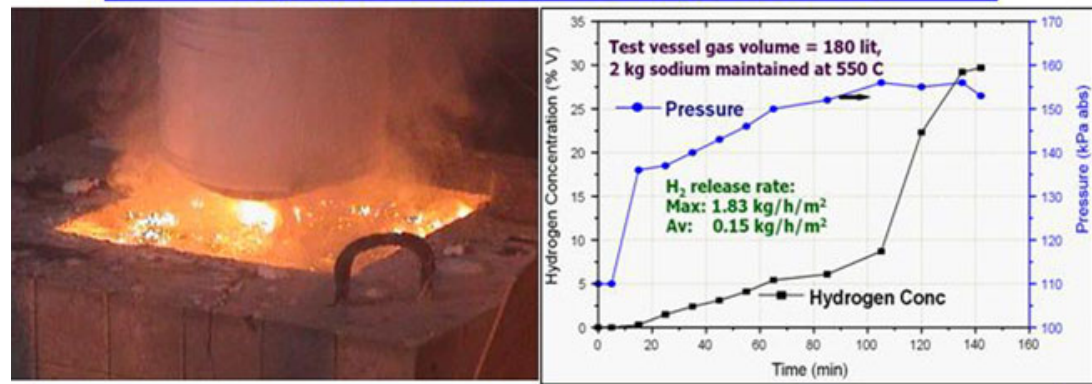

Na concrete interactions (Hydrogen production)

Figure 20. Investigations of chemical toxicity of sodium from basics. 
bundles as well as fuel handling parts. Fuel handling problems have been experienced in FBTR, JOYO (Japanese reactor) and BN type reactors (Russian).

Under sodium safety engineering studies towards FBR, basic aspects of sodium fire capturing the single sodium particle fire scenarios which depicts the 'shrinking core concept are studied with the ultimate objective of developing sodium fire codes. With such codes, it is expected that the pressure and temperature rises in the RCB and SG buildings would be realistic. The sodium fire and subsequent cable fire scenarios have been depicted by innovative experiments (figure 20). The sodium concrete interaction effects in particular hydrogen production are studied based on extensive experimentations (figure 20).

Based on various R\&D activities, it has been concluded that, by close scrutiny and taking into account the advantages gained through sodium cooling, the SFRs do not have any significant disadvantage. These attractive safety aspects can assure a positive trend in the establishment of breeder reactor safety.

Sodium reacts with water violently generating hydrogen, temperature and pressure. Such sodium water reaction (SWR) is possible in a SG, where sodium and water co-exists (in case of a sodium leak). Though the experience of more than 20 years of operation of FBTR-SG is extremely satisfactory (no single leak has been observed), the international experience indicates that a possibility of SWR in SG cannot be ruled out. With a good sensitivity of the hydrogen detection system in sodium at outlet of each SG, timely detection of leak in SG is possible. When a leak is confirmed in a SG module, isolation of affected module both on steam-water and sodium sides, is carried out automatically. Steam-water side is depressurized and is nitrogen blanketed. This prevents further leak and tube wastages and hence prevents a large SWR. In case of large SWR, rupture discs fitted in the inlet and outlet lines of SG module opens out, directs the SWR reaction products to the sodium storage tank and limits the maximum pressure rise in the circuit. The number of design basis leaks in SG is decided by the resulting pressure that can initiate the rupture disc break, for which the entire secondary sodium circuit components including the intermediate heat exchangers are designed.

\section{Conclusions}

Nuclear energy in particular fast breeder reactor with closed fuel cycle is an inevitable technology to form a vital part of diverse portfolio of energy resources. India has to mature and master this technology for achieving sustainable energy growth. FBTR has provided substantial and valuable maintenance and operating experience of sodium cooled fast reactors. PFBR is designed as a techno-economic demonstrator and also a fore runner in the series of SFRs planned in India. Beyond PFBR, economic competitiveness is important for rapid commercial deployment of SFRs. Roadmap with comprehensive R\&D for the large scale deployment of SFRs and timely introduction of metallic fuel reactors with emphasis on breeding gain and enhanced safety is being pursued in a systematic manner at IGCAR. Collaborations with a large number of academic and research institutions in India and abroad would provide high confidence to reach maturity in this challenging technology and also attain a leadership position.

\section{Acknowledgements}

The science and technology contributions by the team of scientists and engineers from Indira Gandhi Centre for Atomic Research (IGCAR), BHAVINI, collaborating institutes and industries are sincerely acknowledged. 


\section{Further reading}

Anil Kakodkar 2007 Emerging Indian nuclear power programme. Paris, France: Technical Talk at AREVA

Baldev Raj 2008 Science and technology of fast breeder reactor programme in India: Challenges and achievements. Prof. Jai Krishna Memorial Award 2008, Annual Convention of INAE, Goa

Baldev Raj, Vasile A, Kagramanian V, Xu M, Nakai R, Kim Y I, Usanov V, Depisch F, Stanculescu A 2009 Assessment of compatibility of a system with fast reactors with sustainability requirements and paths to its development, IAEA-CN-176-05-11, International Conference on Fast Reactors and Related Fuel Cycles: Challenges and Opportunities (FR09). Kyoto, Japan

Chetal S C, Balasubramanian V, Chellapandi P, Mohanakrishnan P, Puthiyavinayagam P, Pillai C P, Raghupathy S, Shanmugham T K and Sivathanu Pillai C 2006 Design of the Prototype Fast Breeder Reactor. Nuclear Engineering and Design 236: 852-860

Chetal S C, Chellapandi P, Mohanakrishnan P, Pillai C P, Puthiyavinayagam P, Selvaraj P, Shanmugam T K and Sivathanu Pillai C 2007 Safety Design of Prototype Fast Breeder Reactor, ICAPP-2007. France

Chetal S C, Chellapandi P, Puthiyavinayagam P, Raghupathy S, Balasubramaniyan V, Selvaraj P, Mohanakrishnan P and Baldev Raj 2009 A perspective on development of future FBRs in India. Int. Conference on Fast Reactors and Related Fuel Cycles: Challenges and Opportunities (FR09). Kyoto, Japan

Chellapandi P, Chetal S C and Baldev Raj 2009 Investigation of structural mechanics failure modes in FBR. Pressure Vessels and Piping, vol. I, Codes, Standards, Design and Analysis, B K Baldev Raj, K Choudary, Velusamy (eds) pp 89-102, New Delhi: Nerosa Publishing house

Chellapandi P, Puthiyavinayagam P, Balasubramaniyan V, Ragupathy S, Rajan Babu V, Chetal S C and Baldev Raj 2010 Design concepts for reactor assembly components of 500 MWe Future SFRs. Nuclear Engineering International, 240: 2948-2956

Grover R B and Subhash Chandra 2004 Strategy for growth of electric energy in India, DAE Publication. Document No-10

Guidez J, Martin L, Chetal S C, Chellapandi P and Baldev Raj 2008 Lessons learned from sodium-cooled fast reactor operation and their ramifications for future reactors with respect to enhanced safety and reliability. Nuclear Tech 164: 207-220

Gen-IV 2007 International Forum Annual Report

Integrated Energy Policy Report of the Expert Committee 2006 New Delhi: Government of India, Planning Commission

INPRO 2010 Assessment of nuclear energy systems based on a closed nuclear fuel cycle with fast reactors. IAEA-TECDOC-1639

Meeting on in-service inspection and monitoring of LMFBRS 1980 International Working Group on Fast Reactors, Bensberg, Germany F.R

Ramachandran Arcot and Gururaj J 1999 Perspective on energy R\&D and next generation technologies. 86th Session of the Indian Science Congress, Chennai, India

Summary Report, 1981 International Working Group on Fast Reactors, 15th annual meeting

Statement by Dr. Anil Kakodkar, 2005, Vienna: 49th General Conference 